\title{
Identification of Sources of Resistance to Phoma medicaginis Isolates in Medicago truncatula SARDI Core Collection Accessions, and Multigene Differentiation of Isolates
}

\author{
Simon R. Ellwood, Lars G. Kamphuis, and Richard P. Oliver
}

Australian Centre for Necrotrophic Fungal Pathogens, State Agricultural Biotechnology Centre, Health Sciences, Murdoch University, Perth 6150, Western Australia.

Accepted for publication 7 July 2006.

\begin{abstract}
Ellwood, S. R., Kamphuis, L. G., and Oliver, R. P. 2006. Identification of sources of resistance to Phoma medicaginis isolates in Medicago truncatula SARDI core collection accessions, and multigene differentiation of isolates. Phytopathology 96:1330-1336.

Phoma medicaginis is a necrotrophic fungal pathogen, commonly found infecting the annual medic Medicago truncatula. To differentiate eight $P$. medicaginis isolates, five gene regions were examined: actin, $\beta$ tubulin, calmodulin, translation elongation factor $1-\alpha(\mathrm{EF}-1 \alpha)$, and the internal transcribed spacer ribosomal DNA. Sequence comparisons showed that specimens isolated from M. truncatula in Western Australia formed a group that was consistently different from, but allied to, a

variable 55-bp repeat unit, which forms the basis of a rapid polymerase chain reaction-based method of reliably distinguishing isolates. Characterization of three isolates showed that all exhibited a narrow host range, causing disease only in $M$. sativa and $M$. truncatula among eight commonly cultivated legume species sampled. Infection of $86 \mathrm{M}$. truncatula single-seeded accessions showed a continuous distribution in disease phenotypes, with the majority of accessions susceptible. On a 1-to-5 disease reaction scale increasing in severity, individual fungal isolates showed means of 2.6 to 3.2 , and scores ranged from 1 to 4.8 among accessions. The results presented here suggest that $M$. truncatula harbors specific and diverse sources of resistance to individual $P$. medicaginis genotypes.
\end{abstract} P. medicaginis var. medicaginis type specimen. EF- $1 \alpha$ contained a hyper-
Phoma medicaginis is one of the most serious necrotrophic pathogens on Medicago sativa (alfalfa) in temperate and Mediterranean regions $(20,28,39)$. On this crop, the disease is known as spring black stem and leaf spot. Disease symptoms typically include seedling blight, stem canker, and leaf spot. Infected leaves undergo chlorosis and defoliate, while stem and petiole lesions may progress, causing crown and root rot. The disease spreads rapidly in cool and wet conditions because pycnidia within lesions disperse conidia by rain splash.

P. medicaginis is also a significant pathogen on M. truncatula in Australia, where M. truncatula is one of the most widely grown annual medics, often in legume pasture-cereal rotations $(11,34)$. Reductions in seed and herbage yield occur, with almost complete defoliation and premature death in the most susceptible cultivars $(1,3)$. M. truncatula is widely recognized as a model for legume genomics and as a reference species to identify important genes in crop species through comparative mapping $(10,44,45)$. Increasingly, this species also is being used to dissect the genetic basis of resistance to necrotrophic diseases and to identify new sources of resistance that may not be available in crops; for example, against Aphanomyces euteiches (32), Ascochyta rabiei, and A. lentis (T. Pfaff, personal communication), Colletotrichum trifolii (41),

Corresponding author: S. R. Ellwood; E-mail address: S.Ellwood@murdoch.edu.au

S. R. Ellwood and L. G. Kamphuis contributed equally to this research and thus are joint first authors.

* The $\boldsymbol{e}$-Xtra logo stands for "electronic extra" and indicates that Figure 1 appears in color online.

DOI: 10.1094/PHYTO-96-1330

(C) 2006 The American Phytopathological Society
Fusarium oxysporum (J. Lichtenzveig, personal communication), and Phytophthora medicaginis (N. D'Souza, personal communication).

Previous studies in annual Medicago spp. have shown genetic variability in Phoma medicaginis resistance (31), although no extensive screens have been carried out in M. truncatula itself. This study uses accessions from the South Australian Research and Development Institute (SARDI) core collection. The core collection was created by Skinner et al. (37) using over 4,000 M. truncatula accessions collected from the Mediterranean basin since the 1960s, and contains three subspecies as defined by Heyn on the basis of pod characteristics (23): M. truncatula subsp. truncatula, longeaculeata, and tricycla. The core is highly diverse, with an average of 25 microsatellite alleles per locus among 192 different accession individuals sampled (12).

Phoma isolates causing disease on Medicago spp. normally are ascribed to P. medicaginis Malbr. \& Roum. in Roum. var. medicaginis Boerema (syn. P. herbarum Westend. var. medicaginis Fckl. and Ascochyta imperfecta Peck), an ascomycete with no known teleomorph. The CABI Bioscience world database of fungal names lists $P$. medicaginis as occupying the group Incertae sedis (of uncertain placement) within the class Dothideomycetes and subclass Pleosporales. Phoma is a complex genus that has been described as the anamorph phase of a number of different species, such as Didymella rabiei and Mycosphaerella pinodes. The Phoma isolates in this study originally were identified on the basis of morphology, the major distinction with Ascochyta spp. being conidial size and aseptate conidia $(5,8)$. However, these features are poorly defined and inconsistent, making classification of Phoma spp. difficult (15). Genetic studies have helped to resolve relatedness, particularly among Ascochyta species $(7,14,33)$.

The objectives of this study were to distinguish $P$. medicaginis genotypes isolated from Medicago truncatula by examining phylo- 
genetically informative gene regions, to evaluate SARDI core accessions for sources of resistance to $P$. medicaginis, and examine the interaction between pathogen genotype and host resistance.

\section{MATERIALS AND METHODS}

Fungal isolates. All available $P$. medicaginis isolates recovered from M. truncatula in Western Australia (WAC4736, 4738, 4741, 7977, and 7980) were obtained from the Department of Agriculture and Food, Western Australia (DAFWA, South Perth, Western Australia). Isolates OMT1 and OMT5 were isolated from naturally infected M. truncatula in Perth, Western Australia. P. medicaginis var. medicaginis CBS316.90 and P. pinodella CBS318.90 standard reference cultures were acquired from Centraalbureau voor Schimmelcultures (Utrecht, The Netherlands). Other species sequenced in this study from DAFWA included Leptosphaerulina trifolii WAC6693, P. pinodella WAC7978, P. exigua WAC7988, and Ascochyta lentis SATAL (Table 1). Representative cultures of OMT1 and OMT5 have been deposited with DAFWA.

Fungal isolation and culture. Isolates OMT1 and OMT5 were isolated by surface sterilization of diseased material (5\% ethanol and $1 \%$ sodium hypochlorite for $1 \mathrm{~min}$ ), followed by rinsing with distilled water and plating onto tap water agar with benzimidazole (50 ppm). The plates were incubated at $22^{\circ} \mathrm{C}$ for 24 to $48 \mathrm{~h}$, and the leading edge of colonies subcultured onto wheat meal agar (WMA; $12 \mathrm{~g}$ of ground wheat meal, $12 \mathrm{~g}$ of agar, and 1 liter of distilled water). Conidia were harvested at 14 days and single spore cultures produced to ensure homogeneity.

DNA isolation and sequencing. Fungal isolates were grown in $10 \mathrm{ml}$ of half-strength potato dextrose broth (19.5 $\mathrm{g}$ of potato dextrose and 1 liter of distilled water) (Becton Dickinson, Franklin Lakes, NJ) at $22^{\circ} \mathrm{C}$ for $48 \mathrm{~h}$. Mycelial mats were blotted to remove excess medium. Genomic DNA was obtained by modifying a protocol described by Matallana et al. (30). Fungal material (0.1 to $0.2 \mathrm{~g}$ ) was ground in liquid nitrogen, homogenized in $500 \mu \mathrm{l}$ of extraction buffer $(50 \mathrm{mM}$ Tris, $\mathrm{pH} 8,25 \mathrm{mM}$ EDTA, $\mathrm{pH} 8$, $100 \mathrm{mM} \mathrm{NaCl}$, and $1 \%$ sodium dodecyl sulfate), combined with $20 \mu \mathrm{l}$ of proteinase $\mathrm{K}$ (Sigma) at $2.5 \mathrm{mg} / \mathrm{ml}$, and incubated at $65^{\circ} \mathrm{C}$ for $1 \mathrm{~h}$. The samples were extracted with an equal volume of phenol/chloroform/isoamyl alcohol (25:24:1, vol/vol). DNA was precipitated with 0.1 volume of $3 \mathrm{M}$ sodium acetate $(\mathrm{pH} 6)$ and 0.7 volume of isopropanol and pelleted at $20,000 \times g$ for $15 \mathrm{~min}$. The samples were washed with $80 \%$ ethanol, resuspended in $100 \mu \mathrm{l}$ of Tris-EDTA (10 mM Tris and $1 \mathrm{mM}$ EDTA, $\mathrm{pH} 8)$, and treated with $1 \mu \mathrm{l}$ of RNAase $\left(10 \mathrm{mg} / \mathrm{ml}, 1 \mathrm{~h}\right.$ at $\left.37^{\circ} \mathrm{C}\right)$.
Polymerase chain reaction amplification and DNA sequencing. The internal transcribed spacer (ITS) ribosomal DNA (rDNA) region is of limited value in resolving closely related species or strains, as shown for example in the genera Botryosphaeria (38) and Cladosporium (43). Therefore, four additional phylogenetically informative regions-actin, $\beta$-tubulin, calmodulin, and translation elongation factor $1 \alpha(\mathrm{EF}-1 \alpha)$-were examined for their effectiveness in distinguishing isolates.

Primers ITS1 and ITS4 (42) were used to amplify ITS1, the 5.8S subunit, and ITS2 of rDNA. Primers bt $2 \mathrm{a}$ and $\mathrm{Bt} 2 \mathrm{~b}$ were used to amplify $\beta$-tubulin (19). $\beta$-Tubulin, calmodulin, and EF- $1 \alpha$ gene regions were amplified using primer sets described by Carbone and Kohn (9). We designed P. medicaginis-specific elongation factor nested intron (EFNI)-1 $\alpha$ primers to sequence beyond G/C-rich stretches. Primer sequences were forward, 5'-CACACCACCATGCCCACA-3' and reverse, 5'-TTAGCATCTTGTCTTGAAACCT-3'.

Actin primers were designed to anneal to conserved regions of the Actl gene in Septoria tritici (GenBank AJ300310), Cercospora beticola (AF443281), Botryotinia fuckeliana (AJ000335), Cladosporium herbarum (AJ300320), and Colletotrichum gloeosporioides (AF112537). The primers amplify an approximately 400-bp intron-spanning fragment. Primer sequences were forward, 5'-TTGACCGACTACCTCATGAAGT-3' and reverse, 5'-AGATACCTGGGTACATGGTGGT-3'.

Polymerase chain reaction (PCR) products were purified with UltraClean PCR Cleanup columns (MolBio, Solana Beach, CA). Amplicons were direct sequenced with BigDye v. 3.1 Terminator Cycle Sequencing Ready Reaction Mix (ABI, Foster City, CA) and run on an ABI Prism 377 DNA sequencer.

Phylogenetic analyses. To compare $P$. medicaginis isolates from $M$. truncatula with related species, ITS sequence data from the six additional species sequenced in this study (Table 1) and ITS sequences from eight GenBank ITS species were assembled. The most closely related GenBank sequences were $D$. applanata DAP428170, D. bryoniae AF297228, D. pinodes AF362064, Epicoccum nigrum AF455455, P. glomerata PGL428533, and P. herbarum AY293803. Leptosphaeria maculans L07735 and Phaeosphaeria nodorum PNU77362 were selected as distant Dothideomycetes.

Alignments were generated using the ClustalW algorithm in BioEdit v.5.0.9 (21). Gaps were treated as a fifth character, and all ambiguous characters and parsimony uninformative characters were excluded prior to analysis. Partition homogeneity tests (25) were conducted using PAUP* version $4.0 \mathrm{~b} 10$ (40) to determine

TABLE 1. Fungal isolates and GenBank accession numbers for gene regions used in this study

\begin{tabular}{|c|c|c|c|c|c|c|c|c|}
\hline \multirow[b]{2}{*}{ Species } & \multirow[b]{2}{*}{ Isolate/source ${ }^{\mathrm{b}}$} & \multirow[b]{2}{*}{ Host } & \multirow[b]{2}{*}{ Date, location } & \multicolumn{5}{|c|}{ GenBank accession numbers ${ }^{\mathrm{a}}$} \\
\hline & & & & Actin & $\beta$-Tubulin & Calmodulin & EFNI- $1 \alpha$ & ITS $^{c}$ \\
\hline $\begin{array}{l}\text { Ascochyta lentis } \\
\text { Leptosphaerulina }\end{array}$ & WAC SATAL & $\begin{array}{l}\text { Lens culinaris } \\
\text { Medicago }\end{array}$ & 1998, Merredin, WA & $\ldots$ & $\ldots$ & $\ldots$ & $\ldots$ & AY131201 \\
\hline Phoma exigua & WAC7988 & M. sativa & 1981, Harvey, WA & $\ldots$ & $\ldots$ & $\ldots$ & $\ldots$ & AY131200 \\
\hline$P$. pinodella & CBS318.90 & Pisum sativum & 1990, Netherlands & $\ldots$ & $\ldots$ & $\ldots$ & $\ldots$ & AY831562 \\
\hline P. pinodella & WAC7978 & M. truncatula & 1981, Perth, WA & $\ldots$ & $\ldots$ & $\ldots$ & $\ldots$ & AY831556 \\
\hline P. medicaginis & WAC4736 & M. truncatula & 1986, Gnowangerup, WA & AY831528 & AY831516 & AY831539 & AY831553 & AY831561 \\
\hline P. medicaginis & WAC4738 & M. truncatula & 1986, Gnowangerup, WA & AY831527 & AY831515 & AY831538 & AY831552 & AY831560 \\
\hline P. medicaginis & WAC4741 & M. truncatula & 1986, Gnowangerup, WA & AY831526 & AY831514 & AY831537 & AY831551 & AY831559 \\
\hline P. medicaginis & WAC7977 & M. truncatula & 1981, Perth, WA & AY 831524 & AY831512 & AY831536 & AY831550 & AY831557 \\
\hline P. medicaginis & WAC7980 & M. truncatula & 1981, Perth, WA & AY831522 & AY831510 & AY831534 & AY831549 & AY831555 \\
\hline $\begin{array}{l}\text { P. medicaginis var. } \\
\text { medicaginis }\end{array}$ & CBS316.90 & M. sativa & 1990, Czechoslovakia & AY831530 & AY831518 & AY831541 & AY831548 & AY831563 \\
\hline
\end{tabular}

a $\mathrm{EFNI}=$ elongation factor nested intron

${ }^{\mathrm{b}}$ Isolates prefixed CBS were obtained from Centraalbureau voor Schimmelcultures (Utrecht, The Netherlands). Isolates prefixed WAC were obtained from the Department of Agriculture and Food, Western Australia (South Perth, Western Australia). The DNA sequences for OMT1 were identical to OMT5 where GenBank accession numbers are not provided. TS = this study.

c ITS = internal transcribed spacer region. 
whether the sequence data from different gene regions were congruent. Phylogenetic analysis based on parsimony was performed on separate and combined data sets in PAUP. The most parsimonious trees were obtained by using heuristic searches with random stepwise addition in 100 replicates, with the tree bisection-reconnection branch-swapping option on and the steepestdescent option off. Maxtrees were unlimited, branches of zero length were collapsed, and all multiple equally most parsimonious trees were saved. Estimated levels of homoplasy and phylogenetic signal (retention and consistency indices) were determined (24). In the initial analyses, all characters were unweighted and unordered; thereafter, characters were reweighted according to the consistency index. Branch and branch node supports were determined using 1,000 bootstrap replicates (16) and characters were sampled with equal probability (however, weights were applied).

Plant cultivation. The $M$. truncatula core collection accessions were acquired from the Genetic Resource Centre, SARDI (GPO Box 397, Adelaide, South Australia 5001). Accessions DZ315 and DZ045 were obtained from the Institut National de la Recherche Agronomique (INRA), Montpellier, France. To ensure homogeneity, a single randomly sampled individual from each accession was single-seeded for two generations. Experiments were conducted in two stages. Isolate pathogenicity on an initial set of $10 \mathrm{M}$. truncatula accessions and the host range among seven other legume species was examined. Virulent isolates then were screened on $86 \mathrm{M}$. truncatula accessions. The initial set of M. truncatula accessions was composed of A17, Borung, DZ315, DZ045, Sa8618, Sa11734, Sa15951, Sa24968, Sa27063, and Sa30199. M. sativa accessions Sa35043, Sa36325, and Sa38082
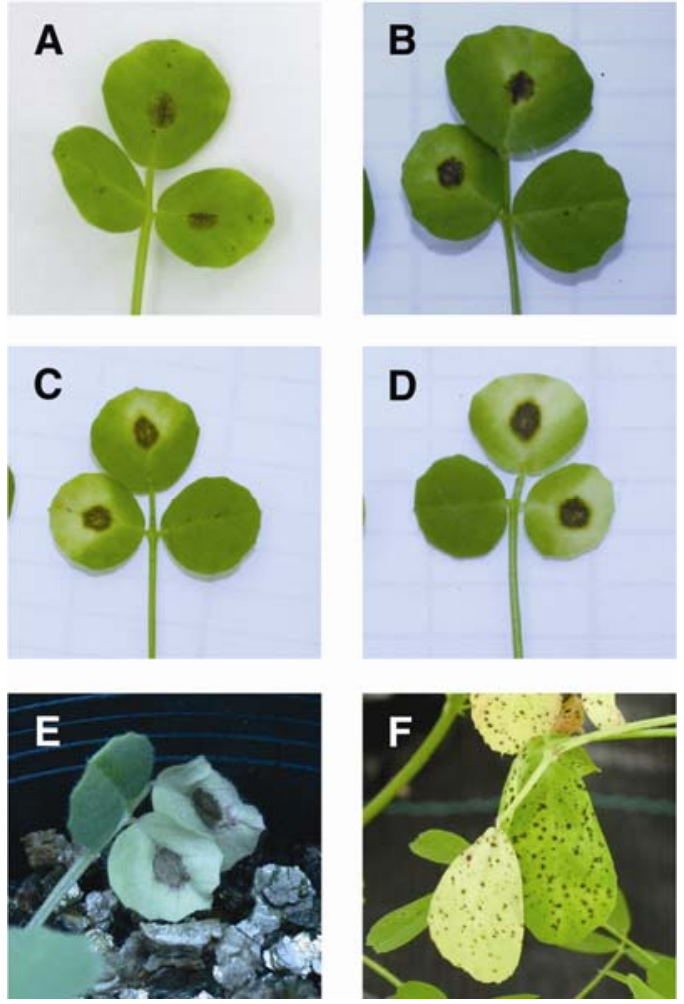

Fig. 1. Phoma medicaginis disease symptoms. A to E, Spot inoculation scoring categories and F, a susceptible Medicago sativa spray-inoculated accession at 10 days postinoculation. Spot inoculation disease reaction (DR) scores: $\mathbf{A}, \mathrm{DR}=1$, small brown or black flecks at the inoculation site (typically $3 \mathrm{~mm}$ in diameter); $\mathbf{B}, \mathrm{DR}=2$, large lesions spreading beyond the inoculation site, chlorosis limited to a 1 - to $2-\mathrm{mm}$ margin around the lesion; $\mathbf{C}, \mathrm{DR}=3$, necrotic lesion and chlorosis covering up to one-third of the leaf area (middle leaf); $\mathbf{D}, \mathrm{DR}=4$, necrotic lesion and chlorosis covering up to four-fifths of the leaf area; $\mathbf{E}, \mathrm{DR}=5$, necrotic lesion, entire leaf chlorotic or dead. were obtained from SARDI. Lupinus albus cv. Kiev Mutant was obtained from the DAFWA. Seed for other cultivars were sourced commercially. These included: Cicer arietinum cv. Sona; Lens culinaris cv. Digger; Lupinus angustifolius cvs. Unicrop, Belara, and Quinlock; Pisum sativum cv. Parafield; M. sativa cv. Sceptre; and Vicia faba cv. Fiord.

To ensure even germination, seed were scarified with sand using a mortar and pestle, transferred to a petri dish lined with blotting paper, and irrigated with sterile water. The seed were held at $4{ }^{\circ} \mathrm{C}$ for $48 \mathrm{~h}$, and germinated at room temperature overnight. Seedlings were sown in pasteurized composted pine bark fines (Richgro Garden Products, Jandakot, Western Australia), and grown under natural light in a temperature-controlled greenhouse (22 and $18^{\circ} \mathrm{C}$, day and night, respectively).

Plant inoculations. Inoculum was prepared by growing fungal isolates on WMA at $22^{\circ} \mathrm{C}$ for 21 to 28 days under UV. Conidia were harvested by incubating plates with $10 \mathrm{ml}$ of distilled water for $20 \mathrm{~min}$. The suspension was filtered through glasswool, adjusted to $1 \times 10^{6}$ spores $/ \mathrm{ml}$, and Tween 20 added to $0.05 \%$. Inoculation of Medicago accessions was performed at the fourth trifoliate stage, or between 3 and 4 weeks of age for species of other legume genera. Two methods of inoculation were used. Initial pathogenicity and host range tests were performed by spraying with an artist's airbrush to runoff, using a rotating platform to ensure an even distribution over plant surfaces. Screens of isolates on 86 M. truncatula accessions used spot inoculation with $10-\mu 1$ droplets of spore suspension on five leaves per plant. These were the unifoliate leaf, the middle and one lateral leaflet of the first trifoliate leaf, and the middle and one lateral leaflet of the second trifoliate leaf. This method was developed because M. truncatula accessions of the SARDI core are highly variable in their growth habit, leaf architecture, and surface characteristics (i.e., presence or absence of leaf hairs), which affects the volume of inoculum adhering to the leaf surface. To ensure high humidity to stimulate conidia germination, plants were placed in sealed propagator trays for $48 \mathrm{~h}$.

A minimum of three plants per replicate pot and three replicates per accession were inoculated. Plants were evaluated macroscopically for disease phenotype at 7 days postinoculation (dpi), and rescored at $10 \mathrm{dpi}$ to confirm more resistant disease reactions. Disease scores of accessions with extreme phenotypes were verified independently. Spray-inoculated plants were evaluated according to the 1-to-5 scale devised by Salter and Leath (36), with an additional class, 0, for complete absence of symptoms. Spotinoculated plants were rated on a related scale as follows: $1=$ small brown or black flecks at the inoculation site (typically $3 \mathrm{~mm}$ in diameter); 2 = large lesions spreading beyond the inoculation site, chlorosis limited to a 1- to 2-mm margin around the lesion; $3=$ necrotic lesion and chlorosis covering up to one-third of the leaf area; $4=$ necrotic lesion and chlorosis covering up to fourfifths of the leaf area; and $5=$ necrotic lesion, entire leaf chlorotic or dead (Fig. 1). Individual accession disease scores were averaged for data comparisons. The statistical software package JMP IN (version 5.1; SAS Institute, Cary, NC) was used to compare means using the Tukey-Kramer honestly significant difference test at $P \leq 0.05$.

\section{RESULTS}

DNA sequencing. Primers designed to amplify each of the five gene regions (ITS rDNA region, actin, $\beta$-tubulin, calmodulin, and EF- $1 \alpha$ ) gave a PCR product in each $P$. medicaginis isolate. However, the EF-1 $\alpha$ universal primers described by Carbone and Kohn (9) gave poor sequencing chromatograms, due to the existence of G-C-rich intron stretches resulting in polymerase slippage and abrupt sequencing signal reduction. The EF-1 $\alpha$ amplicons ranged in size from 600 to $800 \mathrm{bp}$ (not shown), twice the expected length found among other Dothideomycetes. Due to the apparent 
polymorphism, nested $P$. medicaginis-specific intron-targeted primers $(E F N I-1 \alpha)$ were designed to characterize the intervening sequence. GenBank accession numbers for each gene region are given in Table 1.

WAC4736, 4738, 4741, 7977, 7980, OMT1, and OMT5 exhibited a 97.2 to $97.4 \%$ identity in nucleotide composition compared with $P$. medicaginis var. medicaginis CBS316.90 across the five gene regions. This suggests that these isolates are closely allied to, but different from, this reference culture. The majority of nucleotide differences between isolates were accounted for by high polymorphism in EF-1 $\alpha$. Excluding $P$. medicaginis var. medicaginis CBS316.90, calmodulin and EFNI-1 $\alpha$ together resolved four genotypes. Examination of the intron sequences showed the existence of a 55-bp unit repeated five consecutive times in each isolate.

Phylogenetic analyses. The $P$. medicaginis isolates in this study initially were compared with closely related species using ITS sequence data alone because, for most species, only this data was available in GenBank. The aligned data set consisted of 601 characters, of which 80 were parsimony informative. The data set contained significant phylogenetic signal compared with 1,000 random trees $(P<0.01, \mathrm{~g} 1=-0.91)$, and initial heuristic searches resulted in 47 most parsimonious trees.

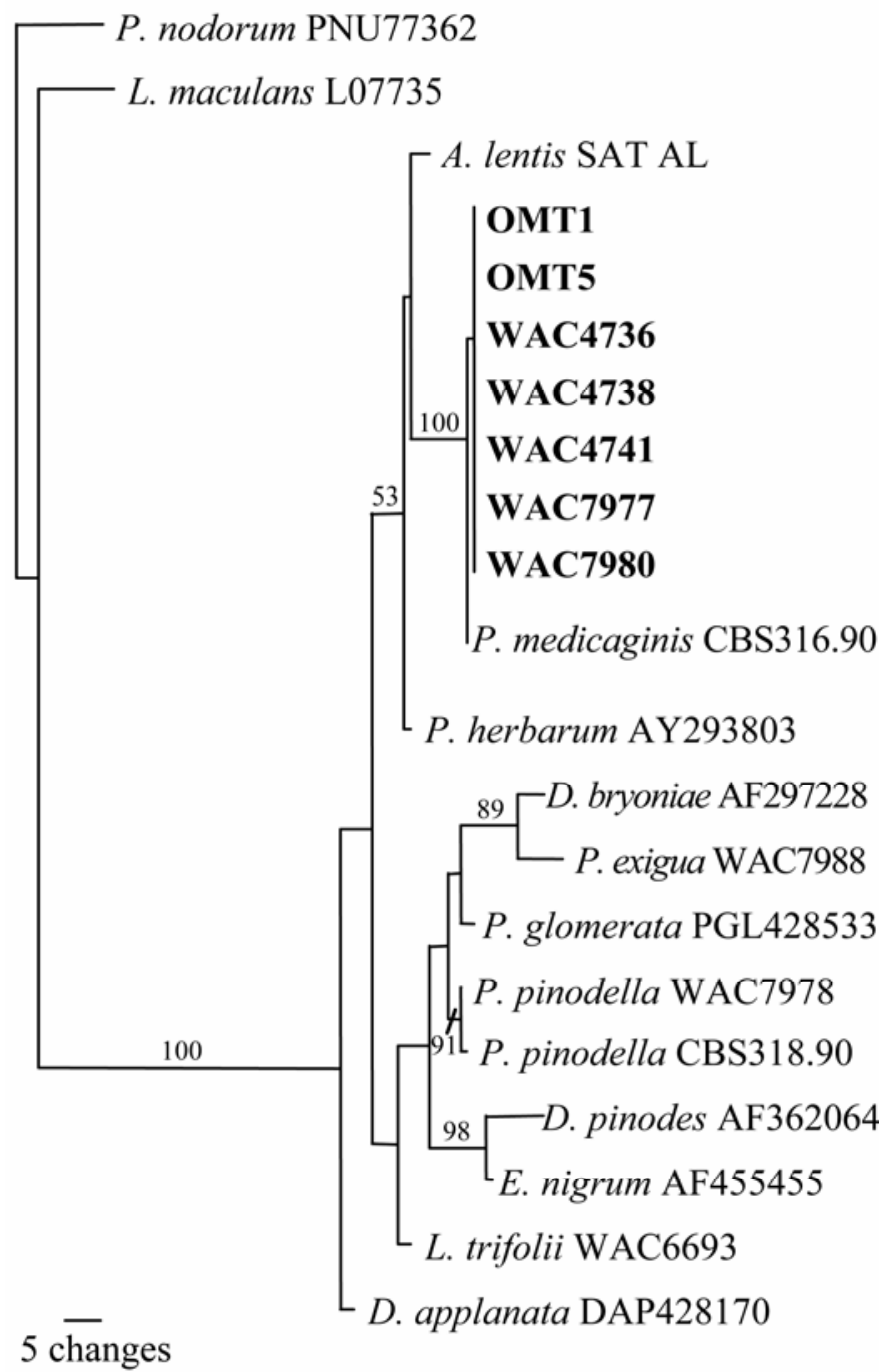

Fig. 2. Phylogram of one of 47 most parsimonious trees based on nuclear DNA internal transcribed spacer region sequence data. Phoma medicaginis isolates obtained from Medicago truncatula in Western Australia are in bold. Tree length is 165 steps $(\mathrm{CI}=0.66, \mathrm{RI}=0.77)$, and branch support (bootstrap values) is given above branches based on 1,000 bootstrap replicates. The tree is rooted to Phaeosphaeria nodorum.
Of these 47 most parsimonious trees, one (Fig. 2) shows that P. medicaginis var. medicaginis CBS316.90 is more similar to $P$. medicaginis isolates from $M$. truncatula than to other fungal species. The tree also shows no clear association between species of the same genus designation and clade, with strong bootstrap support (>80) for D. pinodes grouping with E. nigrum, D. bryoniae with $P$. exigua, and moderate support $(>50)$ for A. lentis grouping with $P$. herbarum and $P$. medicaginis.

EF-1 $\alpha$ showed substantial differences in length and sequence between $P$. medicaginis isolates and other species. The dissimilarity prevented sequence alignments with other species, and therefore phylogenetic analyses using combined gene regions were conducted among $P$. medicaginis isolates only. ITS and calmodulin sequence data were excluded from the analyses because the ITS had no informative regions, and a partition homogeneity test was significant $(P=0.001)$ that EFNI- $1 \alpha$ and calmodulin data were in conflict. The aligned data set of actin, $\beta$-tubulin, and EFNI- $1 \alpha$ consisted of 1,056 characters, of which 46 were parsimony informative. The data set contained significant phylogenetic signal compared with 1,000 random trees $(P<0.01, \mathrm{~g} 1=-1.21)$, and heuristic searches resulted in a single most parsimonious tree (Fig. 3). Isolates WAC4736, WAC4741, and OMT5 were selected as representatives of each of the three genotypic groups of $P$. medicaginis isolates from $M$. truncatula for infection experiments.

Disease evaluations. $P$. medicaginis isolates WAC4736, WAC4741, and OMT5 caused disease only on $M$. sativa and $M$. truncatula and not on any of the other legume species tested. $M$. sativa accessions showed levels of disease equivalent to $M$. truncatula (data not shown, Fig. 1F, spay inoculation symptoms). Disease reaction (DR) scores ranged between 2 and 4 at $7 \mathrm{dpi}$, with clear lesions and pycnidia forming by $10 \mathrm{dpi}$.

Most of the 86 accessions in the M. truncatula core collection were susceptible to $P$. medicaginis (Table 2). Mean DR scores ranged from 2.6 to 3.2 between the isolates, with WAC4741 the most virulent. DR scores among accessions ranged from 1 to 4.8 . Sixteen of the accessions (Sa2193, Sa2715, Sa2729, Sa3054, Sa8618, Sa9062, Sa9357, Sa9596, Sa10964, Sa11734, Sa14829, Sa17562, Sa27774, Sa27784, Sa28089, and Sa28645) were susceptible to all three isolates, with DR scores $\geq 3$. Only accessions Sa1489 and Sa8623, with DR scores $\leq 2$ against each isolate, were considered partially resistant. However, genotype-specific resistance in accessions exhibiting a score $\leq 1.5$ was observed against

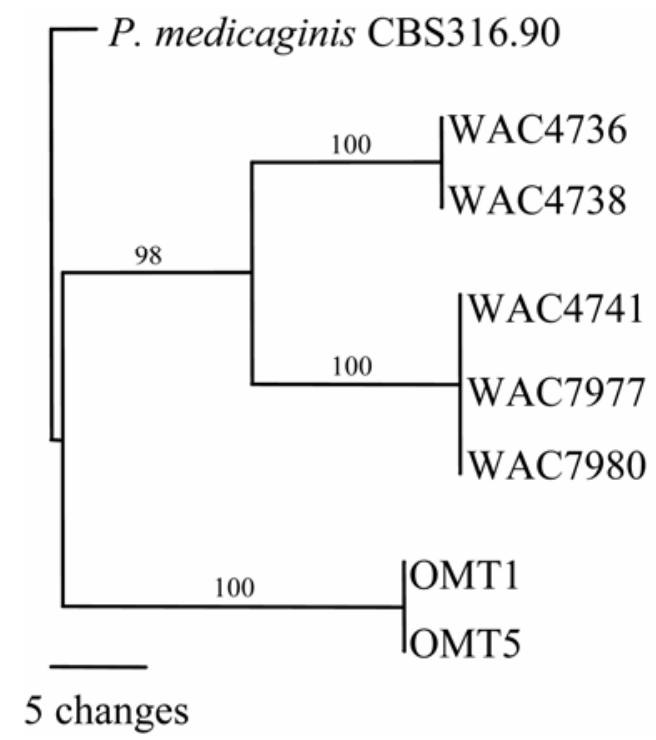

Fig. 3. Single most parsimonious phylogram of Phoma medicaginis isolates based on actin, $\beta$-tubulin, and elongation factor nested intron (EFNI)-1 $\alpha$ sequence data. Tree length is 52 steps $(\mathrm{CI}=0.98, \mathrm{RI}=0.99)$, and branch support (bootstrap values) is given above branches based on 1,000 bootstrap replicates. 
individual isolates. These included Sa396, Sa3047, Sa1502, Sa9119, Sa9456, Sa9707, Sa10481, Sa11753, Sa11954, Sa12451, Sa17498, Sa18346, Sa18543, Sa24576, Sa27063, and Sa28064.

\section{DISCUSSION}

A prerequisite to understanding isolate specificity and host resistance lies in resolving relationships with allied fungal species and between isolates. In the first step, we compared P. medicaginis to the most genetically similar species in GenBank. Twenty predominantly North American $P$. medicaginis ITS sequences available in GenBank and the $P$. medicaginis var. medicaginis CBS316.90 reference culture examined here share the same single nucleotide difference with the isolates in this study. This suggests that the $P$. medicaginis isolates from $M$. truncatula form a group closely related to all other isolates sequenced to date, but that isolates other than those from M. truncatula in Western Australia are distinct, as depicted in the ITS tree and supported in the combined analysis tree.
Maximum parsimony of the ITS regions showed no support for monophyletic genera, but rather strongly supports polyphyly among Phoma and Didymella spp. The number of nucleotide differences indicates that Phoma spp. could be assigned to different genera or, conversely, the genus Leptosphaerulina expanded to incorporate Ascochyta, Epicoccum, and Phoma, assuming GenBank accessions are from correctly identified fungi. Faris-Mokaiesh et al. (14) and Reddy et al. (35) found similar phylogenetic conflicts among Phoma and Didymella spp., whereby two organisms from different genera were more similar than two organisms of the same genus. The ITS tree is not in total agreement with the sections proposed by Boerema et al. (6), based on morphology and generic synonyms. The majority of the species examined here, including $P$. medicaginis, were placed into section Phyllostictoides. However, $P$. herbarum and $E$. nigrum were assigned to sections Phoma and Peyronellaea, respectively, and L. trifolii was designated as miscellaneous. Giraud et al. (18) have suggested that the phylogenetic species concept may be more appropriate than the biological species concept in organisms with life cycles

TABLE 2. Evaluation of 86 South Australian Research and Development Institute accessions for resistance to three genotypes of Phoma medicaginis

\begin{tabular}{|c|c|c|c|c|c|c|c|}
\hline \multirow[b]{2}{*}{ Accession } & \multicolumn{3}{|c|}{ DR score $^{a}$} & \multirow[b]{2}{*}{ Accession } & \multicolumn{3}{|c|}{ DR score ${ }^{a}$} \\
\hline & 4736 & 4741 & OMT5 & & 4736 & 4741 & OMT5 \\
\hline Sa396 & 1.27 & 2.08 & 2.98 & Sa11954 & 2.9 & 4.12 & 1.21 \\
\hline Sa1306 & 1.9 & 3.03 & 1.99 & $\mathrm{Sa} 12451$ & 1.23 & 3.22 & 1.23 \\
\hline Sa1316 & 2.73 & 3.97 & 2.61 & $\mathrm{Sa} 12455$ & 2.1 & 3.29 & 2.08 \\
\hline Sa1489 & 1.07 & 1.53 & 1.34 & Sa14829 & 3.42 & 3.69 & 4.13 \\
\hline Sa1502 & 1 & 3.11 & 2.69 & Sa15951 & 1.7 & 3.26 & 2.73 \\
\hline Sa1516 & 2.57 & 2 & 3.88 & Sa17498 & 2.91 & 1.5 & 4.14 \\
\hline $\mathrm{Sa} 2193$ & 3.6 & 3.26 & 3.8 & Sa17562 & 3.99 & 3.64 & 3.36 \\
\hline $\mathrm{Sa} 2203$ & 1.88 & 4.06 & 2.74 & Sa17590 & 3.37 & 2.64 & 1.36 \\
\hline $\mathrm{Sa} 2715$ & 3.85 & 3.08 & 3.06 & Sa18346 & 2.7 & 1.31 & 1.18 \\
\hline $\mathrm{Sa} 2729$ & 3.53 & 3 & 3.85 & $\mathrm{Sa} 18395$ & 1.87 & 4.62 & 2.61 \\
\hline $\mathrm{Sa} 2841$ & 2.43 & 4.11 & 1.69 & Sa18532 & 3.2 & 3.14 & 1.52 \\
\hline $\mathrm{Sa} 3047$ & 2.37 & 1.26 & 1.84 & Sa18543 & 3.17 & 4.4 & 1 \\
\hline $\mathrm{Sa} 3054$ & 4.43 & 3.98 & 4.14 & Sa19957 & 3.14 & 4.57 & 1.81 \\
\hline Sa3308 & 2.96 & 3.92 & 2.5 & Sa19995 & 3.1 & 2.98 & 2.19 \\
\hline $\mathrm{Sa} 3536$ & 2.23 & 3.08 & 2.26 & Sa19998 & 1.92 & 4.54 & 2.66 \\
\hline Sa3569 & 1.84 & 1.7 & 2.69 & $\mathrm{Sa} 21302$ & 2.19 & 3.17 & 2.16 \\
\hline Sa3749 & 1.63 & 3.25 & 3.53 & $\mathrm{Sa} 21362$ & 1.93 & 2.75 & 3.42 \\
\hline Sa3919 & 4.28 & 2.11 & 4.17 & $\mathrm{Sa} 23859$ & 2.06 & 3.83 & 1.26 \\
\hline $\mathrm{Sa} 4327$ & 1.63 & 2.83 & 3.03 & $\mathrm{Sa} 24576$ & 1.48 & 4.22 & 2.17 \\
\hline $\mathrm{Sa} 4480$ & 1.95 & 2.47 & 3.31 & $\mathrm{Sa} 24968$ & 2.5 & 3.75 & 2.32 \\
\hline Sa4586 & 2.5 & 3.27 & 2.94 & $\mathrm{Sa} 25654$ & 2.25 & 3.92 & 1.93 \\
\hline Sa7749 & 1.6 & 4.42 & 3.87 & $\mathrm{Sa} 25915$ & 2.8 & 3.06 & 2.95 \\
\hline $\mathrm{Sa} 8454$ & 2.2 & 2.14 & 1.38 & $\mathrm{Sa} 25941$ & 3.33 & 3.2 & 1.32 \\
\hline $\mathrm{Sa} 8604$ & 1.54 & 2.32 & 4.1 & $\mathrm{Sa} 27063$ & 3.2 & 2.33 & 1.64 \\
\hline Sa8618 & 3.44 & 3.42 & 3.33 & $\mathrm{Sa} 27192$ & 2.03 & 2.64 & 2.63 \\
\hline $\mathrm{Sa} 8623$ & 1.52 & 2 & 1.48 & $\mathrm{Sa} 27774$ & 4.47 & 4.77 & 3.47 \\
\hline Sa8871 & 3.25 & 2.03 & 2.65 & $\mathrm{Sa} 27784$ & 3.2 & 3.47 & 3.24 \\
\hline $\mathrm{Sa} 9062$ & 3.63 & 3.58 & 3.82 & $\mathrm{Sa} 28064$ & 1.45 & 2.6 & 1.33 \\
\hline Sa9119 & 2.6 & 1.32 & 1.93 & $\mathrm{Sa} 28089$ & 3.97 & 4.22 & 3.13 \\
\hline $\mathrm{Sa} 9141$ & 3.73 & 2.14 & 2.57 & $\mathrm{Sa} 28375$ & 3.4 & 3.9 & 1.72 \\
\hline $\mathrm{Sa} 9295$ & 3.44 & 2.35 & 2.82 & $\mathrm{Sa} 28645$ & 4.23 & 4.23 & 4.82 \\
\hline Sa9357 & 4 & 3.64 & 3.45 & $\mathrm{Sa} 28889$ & 2.27 & 3.93 & 2.79 \\
\hline $\mathrm{Sa} 9456$ & 1 & 3.25 & 2.43 & Sa30199 & 2.4 & 3.93 & 3.54 \\
\hline $\mathrm{Sa} 9596$ & 3.93 & 3.33 & 3.1 & $\mathrm{Sa} 30203$ & 3.62 & 4.62 & 2.38 \\
\hline $\mathrm{Sa} 9670$ & 3.06 & 2.9 & 2.24 & $\mathrm{Sa} 30740$ & 3.42 & 2.9 & 2.81 \\
\hline Sa9707 & 1.2 & 4.32 & 1.14 & $\mathrm{Sa} 31438$ & 2.96 & 4.2 & 3.01 \\
\hline $\mathrm{Sa} 9710$ & 2.48 & 1.24 & 1.88 & A17 & 2.27 & 4 & 4.15 \\
\hline Sa9715 & 1.72 & 3.28 & 1.63 & A20 & 2.43 & 2.92 & 3.2 \\
\hline Sa9856 & 2.22 & 1.58 & 2.12 & Borung & 1.97 & 2.58 & 3.28 \\
\hline Sa9866 & 2.5 & 2.79 & 1.29 & DZ045 & 2.05 & 2.35 & 2.19 \\
\hline Sa9888 & 2.43 & 3.47 & 2.96 & DZ315 & 1.92 & 3.4 & 2.5 \\
\hline Sa10481 & 1.38 & 3.14 & 2.94 & & & & \\
\hline Sa10964 & 3.55 & 4.23 & 4.31 & Range & $1-4.47$ & $1.24-4.77$ & $1-4.82$ \\
\hline Sa11734 & 3.97 & 4.11 & 3.47 & Mean & 2.62 & 3.15 & 2.63 \\
\hline Sa11753 & 3.08 & 1.39 & 2.01 & $\mathrm{LSD}^{\mathrm{b}}$ & 1.22 & 1.11 & 1.05 \\
\hline
\end{tabular}

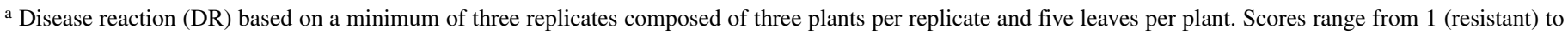
5 (fully susceptible), where $1=$ small brown or black flecks at the inoculation site (typically $3 \mathrm{~mm}$ in diameter); $2=$ large lesions spreading beyond the inoculation site, chlorosis limited to a 1- to 2-mm margin around the lesion; $3=$ necrotic lesion and chlorosis covering up to one-third of the leaf area (middle leaf); 4 = necrotic lesion and chlorosis covering up to four-fifths of the leaf area; and $5=$ necrotic lesion, entire leaf chlorotic or dead.

${ }^{\text {b }}$ Least significant difference (LSD) was calculated using the Tukey-Kramer honestly significant difference test at $P \leq 0.05$. 
involving restricted dispersal between selection on the host and mating, and showed that divergence can occur in sympatry and lead to host race formation, or even speciation, by the mere process of specialization, with strong divergent adaptive selection.

The highly polymorphic $P$. medicaginis EF-1 $\alpha$ 55-bp repeat unit enabled isolate genotypes to be clearly distinguished. The separation of the isolates was consistent with the sum of differences from the ITS, actin, $\beta$-tubulin, and calmodulin gene regions, other features such as colony morphology (not shown), and discrimination comparable with randomly amplified polymorphic DNA analysis (not shown). The repeat was not present among the other species sequenced, and shows no homology to sequences or motifs in GenBank. The nested primers designed to EF-1 $\alpha$ amplify within an intron, where duplication of noncoding DNA provides an explanation for the hypervariable nature of this gene region. Therefore, the EF- $1 \alpha$ intron region provides a specific means of rapidly distinguishing closely related strains.

$P$. medicaginis isolates from $M$. truncatula failed to induce either compatible or incompatible disease phenotypes in legumes other than M. truncatula and the closely related $M$. sativa. This contrasts with previous reports documenting a wide host range for $P$. medicaginis (27), which detailed disease principally among the Papilionoideae, but also within the Brassicaceae and Solanaceae. Many such reports require verification but suggest that $P$. medicaginis var. medicaginis may be a less-discriminating pathogen, and underlines the need for characterization of the population structure, genetic diversity, and host specificity of this species.

A continuous distribution and wide range of disease phenotypes were observed among 86 accessions screened. Previous studies in the $P$. medicaginis $-M$. truncatula pathosystem have found comparably wide ranges in disease symptoms between accessions $(2,31)$. However, this is the first study using genotyped monosporic sources of inoculum and single-seeded accessions. Our results suggest that $M$. truncatula harbors specific and diverse sources of resistance to individual pathogen genotypes, with several isolate-specific resistant accessions showing pronounced susceptibility to a second isolate with a DR score $>4$. In one accession, Sa2841, tissue specificity was observed, with complete resistance in the unifoliate leaf to WAC4736 but not in subsequent trifoliate leaves. Two accessions, Sa1489 and Sa8623, showed resistance to all three isolates. The genetic basis of these broadspectrum resistance phenotypes cannot be determined until the genes responsible have been mapped or isolated.

In contrast to biotrophic pathosystems where race-specific genefor-gene recognition is well established (22), resistance to necrotrophs usually is quantitative in nature, and necrotrophs generally are considered to have a wide host range. However, necrotrophic fungi must be highly specialized in order to promote tissue death and successfully avoid, or suppress, host resistance responses. Phylogenetic analyses recently have helped to define host-preferential clades in some species; for example, among Ascochyta spp. $(4,15)$. Host plant resistance mechanisms against necrotrophs are not well understood but appear to function by interfering with the action of phytotoxins produced by the pathogen: for example, the race-specific $\mathrm{Hml}$ gene in maize (26), the Pyrenophora triticirepentis ToxA-insensitivity $t s n 1$ (13) and ToxB-insensitivity $t s c 2$ (17) loci in wheat, and resistance to the $F$. graminearum mycotoxin deoxynivalenol in wheat (29). Identification of sources of resistance in diverse accessions of $M$. truncatula offers the opportunity to characterize new forms of resistance in this genetically tractable model legume.

\section{ACKNOWLEDGMENTS}

This research was funded by the Grains Research and Development Corporation of Australia. We thank S. Hughes, the curator of Australian Medicago Genetic Resources Centre, for providing seed.

\section{LITERATURE CITED}

1. Barbetti, M. J. 1983. Fungal foliage diseases of pasture legumes. J. Agric. (W. Aust.) 1:10-12.

2. Barbetti, M. J. 1995. Resistance in annual Medicago species to Phoma medicaginis and Leptosphaerulina trifolii on herbage under field conditions. Aust. J. Exp. Agric. 35:209-214.

3. Barbetti, M. J., and Nichols, P. G. H. 1991. Effect of Phoma medicaginis and Leptosphaerulina trifolii on herbage and seed yield and coumestrol content of annual Medicago species. Phytophylactica 23:223-227.

4. Barve, M. P., Arie, T., Salimath, S. S., Muehlbauer, F. J., and Peever, T. L. 2003. Cloning and characterization of the mating type (MAT) locus from Ascochyta rabiei (teleomorph: Didymella rabiei) and a MAT phylogeny of legume-associated Ascochyta spp. Fungal Genet. Biol. 39:151-167.

5. Boerema, G. H., and Bollen, G. H. 1975. Conidiogenesis and conidial septation as differentiating criteria between Phoma and Ascochyta. Persoonia 8:111-144.

6. Boerema, G. H., Noordeloos, M. E., De Gruyer, J., and Hamers, M. E. C. 2004. Phoma Identification Manual: Differentiation of Specific and InfraSpecific Taxa in Culture. CABI Publishing, Wallingford, Oxfordshire, UK.

7. Bouznad, Z., Corbiere, R., Elbiari, A., and Spire, D. 1995. Identification of Ascochyta species of legumes by random amplified polymorphic DNA. Page 78 in: Second European Conference of Grain Legumes AEP, Copenhagen, Denmark.

8. Brewer, J. G., and Boerema, G. H. 1965. Electron microscope observations on the development of pycnidiospores in Phoma and Ascochyta spp. Proc. K. Ned. Akad. Wet. 68:86-97.

9. Carbone, I., and Kohn, L. M. 1999. A method for designing primer sets for speciation studies in filamentous ascomycetes. Mycologia 91:553-556.

10. Choi, H.-K., Kim, D., Uhm, T., Limpens, E., Lim, H., Mun, J.-H., Kalo, P., Penmetsa, R. V., Seres, A., Kulikova, O., Roe, B. A., Bisseling, T., Kiss, G. B., and Cook, D. R. 2004. A sequence-based genetic map of Medicago truncatula and comparison of marker colinearity with $M$. sativa. Genetics 166:1463-1502.

11. Crawford, E. J., Lake, A. W. H., and Boyce, K. G. 1989. Breeding annual Medicago species for semi-arid conditions in southern Australia. Adv. Agron. 42:399-437.

12. Ellwood, S. R., D'Souza, N. K., Kamphuis, L. G., Burgess, T. I., Nair, R. M., and Oliver, R. P. 2006. SSR analysis of the Medicago truncatula SARDI core collection reveals substantial diversity and unusual genotype dispersal throughout the Mediterranean basin. Theor. Appl. Genet. 112:977-983.

13. Faris, J., Anderson, J., Francl, L., and Jordahl, J. 1996. Chromosomal location of a gene conditioning insensitivity in wheat to a necrosisinducing culture filtrate from Pyrenophora tritici-repentis. Phytopathology $86: 459-463$.

14. Faris-Mokaiesh, S., Boccara, M., Denis, J. B., Derrien, A., and Spire, D. 1996. Differentiation of the "Ascochyta complex" fungi of pea by biochemical and molecular markers. Curr. Genet. 29:182-190.

15. Fatehi, J., Bridge, P. D., and Punithalingam, E. 2003. Molecular relatedness within the "Ascochyta pinodes-complex." Mycopathologia 156:317327.

16. Felsenstein, J. 1985. Confidence limits on phylogenies: an approach using the bootstrap. Evolution 39:783-791.

17. Friesen, T. L., and Faris, J. D. 2004. Molecular mapping of resistance to Pyrenophora tritici-repentis race 5 and sensitivity to Ptr ToxB in wheat. Theor. Appl. Genet. 109:464-471.

18. Giraud, T., Villaréal, L. M. M. A., Austerlitz, F., Le Gac, M., and Lavigne, C. 2006. Importance of the life cycle in sympatric host race formation and speciation of pathogens. Phytopathology 96:280-287.

19. Glass, N. L., and Donaldson, G. C. 1995 . Development of primer sets designed for use with the PCR to amplify conserved genes from filamentous ascomycetes. Appl. Environ. Microbiol. 61:1323-1330.

20. Graham, J. H., Frosheiser, F. I., Stuteville, D. L., and Erwin, D. C. 1979. A Compendium of Alfalfa Diseases. The American Phytopathological Society, St. Paul, MN.

21. Hall, T. A. 1999. BioEdit: A user-friendly biological sequence alignment editor and analysis. Nucleic Acids Symp. Ser. 41:95-98.

22. Hammond-Kosack, K. E., and Parker, J. E. 2003. Deciphering plantpathogen communication: Fresh perspectives for molecular resistance breeding. Curr. Opin. Biotechnol. 14:177-193.

23. Heyn, C. 1963. The annual species of Medicago. Scripta Hierosolymitana 12:1-154.

24. Hillis, D. M., and Huelsenbeck, J. P. 1992. Signal, noise, and reliability in molecular phylogenetic analyses. J. Hered. 83:189-195.

25. Huelsenbeck, J. P., Bull, J. J., and Cunningham, C. V. 1996. Combining data in phylogenetic analysis. Tree 11:152-158.

26. Johal, G. S., and Briggs, S. P. 1992. Reductase activity encoded by the $H M 1$ disease resistance gene in maize. Science 258:985-987. 
27. Kinsey, G. C. 2002. Phoma medicaginis. Report No. 1503. CABI Bioscience, Egham, Surrey, UK.

28. Lamprecht, S. C., and Knox-Davies, P. S. 1984. Preliminary survey of foliage diseases of annual Medicago spp. in South Africa. Phytophylactica 16:177-183.

29. Lemmens, M., Scholz, U., Berthiller, F., Dall'Asta, C., Koutnik, A., Schuhmacher, R., Adam, G., Buerstmayr, H., Mesterhazy, A., Krska, R., and Ruckenbauer, P. 2005. The ability to detoxify the mycotoxin deoxynivalenol colocalizes with a major quantitative trait locus for Fusarium head blight resistance in wheat. Mol. Plant-Microbe Interact. 18:1318-1324.

30. Matallana, E., Bell, C. J., Dunn, P. J., Lu, M., and Ecker, J. R. 1992. Genetic and physical linkage of the Arabidopsis genome: Methods for anchoring yeast artificial chromosomes. Pages 144-169 in: Methods in Arabidopsis Research. C. Koncz, N. H. Chua, and J. Schell, eds. World Scientific, Singapore.

31. O'Neill, N., Bauchan, G., and Samac, D. 2003. Reactions in the annual Medicago spp. core germ plasm collection to Phoma medicaginis. Plant Dis. 87:557-562.

32. O'Neill, N. R., and Bauchan, G. R. 2000. Sources of resistance to anthracnose in the annual Medicago core collection. Plant Dis. 84:261267.

33. Onfroy, C., Tivoli, B., Corbiere, R., and Bouznad, Z. 1999. Cultural, molecular, and pathogenic variability of Mycosphaerella pinodes and Phoma medicaginis var. pinodella isolates from dried pea (Pisum sativum) in France. Plant Pathol. 48:218-229.

34. Pearson, C. J., Brown, R., Collins, W. J., Archer, K. A., Wood, M. S., Petersen, C., and Bootle, B. 1997. An Australian temperate pastures database. Aust. J. Agric. Res. 48:453-466.

35. Reddy, P. V., Patel, R., and White, J. F. 1998. Phylogenetic and developmental evidence supporting reclassification of cruciferous pathogens Phoma lignam and Phoma wasabiae in Plenodomus. Can. J. Bot. 76:1916-1922.
36. Salter, R. M., and Leath, K. L. 1992. Spring back stem and leafspot resistance. In: Standard Tests to Characterize Alfalfa Cultivars. C. C. Fox, R. Berberet, F. A. Gray, C. R. Grau, D. L. Jessen, and M. A. Petersen, eds. North American Alfalfa Improvement Conference, Beltsville, MD.

37. Skinner, D., Bauchan, G., Auricht, G., and Hughes, S. 1999. A method for the efficient management and utilization of large germplasm collections. Crop Sci. 39:1237-1242.

38. Slippers, B., Fourie, G., Crous, P. W., Coutinho, T. A., Wingfield, B. D., and Wingfield, M. J. 2004. Multiple gene sequences delimit Botryosphaeria australis sp. nov. from B. lutea. Mycologia 96:1030-1041.

39. Smith, I. M., Dunez, J., Phillips, D. H., Lelliot, R. A., and Archer, S. A. 1988. European Handbook of Plant Diseases. Blackwell Scientific, London.

40. Swofford, D. L. 2001. PAUP*. Phylogenetic analysis using parsimony (* and other methods). Version 4. Sinauer Associates, Sunderland, MA

41. Torregrosa, C., Cluzet, S., Fournier, J., Huguet, T., Gamas, P., Prosperi, J., Esquerre-Tugaye, M., Dumas, B., and Jacquet, C. 2004. Cytological, genetic, and molecular analysis to characterize compatible and incompatible interactions between Medicago truncatula and Colletotrichum trifolii. Mol. Plant-Microbe Interact. 17:909-920.

42. White, T. J., Bruns, T., Lee, S., and Taylor, J. 1990. Amplification and direct sequencing of fungal ribosomal RNA genes for phylogenetics. Pages 315-322 in: PCR Protocols. D. H. Innis, D. H. Gelfand, J. J. Sninsky, and T. J. White, eds. Academic Press, New York.

43. Wirsel, S. G. R., Runge-Frobose, C., Ahren, D. G., Kemen, E., Oliver, R. P., and Mendgen, K. W. 2002. Four or more species of Cladosporium sympatrically colonize Phragmites australis. Fungal Genet. Biol. 35:99113.

44. Young, N., Mudge, J., and Ellis, T. 2003. Legume genomes: More than peas in a pod. Curr. Opin. Plant Biol. 6:199-204.

45. Zhu, H., Choi, H.-K., Cook, D. R., and Shoemaker, R. C. 2005. Bridging model and crop legumes through comparative genomics. Plant Physiol. 137:1189-1196. 